\title{
Miniestaquia seriada no rejuvenescimento de clones de Eucalyptus ${ }^{(1)}$
}

\author{
Ivar Wendling ${ }^{(2)}$ e Aloisio Xavier ${ }^{(3)}$
}

\begin{abstract}
Resumo - O objetivo deste trabalho foi avaliar a eficiência da técnica de miniestaquia seriada em quatro clones de Eucalyptus grandis, quanto à sobrevivência, ao enraizamento e ao crescimento em altura e diâmetro de colo das mudas. Foram realizados sete subcultivos pela miniestaquia seriada, por enraizamento sucessivo de brotações de minicepas, em casa de vegetação durante 25 dias, seguido de aclimatação por dez dias em casa de sombra e avaliação final das mudas aos 50 dias de idade, em pleno sol. A miniestaquia seriada mostrou efeito positivo, principalmente em relação aos clones que apresentaram menor potencial de enraizamento.
\end{abstract}

Termos para indexação: enraizamento, clonagem, silvicultura, propagação vegetativa.

\section{Serial minicuttings technique as a rejuvenation method for Eucalyptus clones}

\begin{abstract}
The objective of this work was to evaluate the efficiency of serial minicuttings technique in four clones of Eucalyptus grandis, regarding to survival, rooting and growth in height and diameter of the seedlings. Seven subcultures, by serial minicuttings technique, through successive rooting of the sprouts were accomplished. Rooting was carried out in a greenhouse during 25 days, followed by ten days acclimatization at shadow house, and final evaluation of the seedlings at 50 days, in the sun. The serial minicuttings technique showed positive effect, mostly for difficult rooting clones.
\end{abstract}

Index terms: rooting, cloning, forestry, vegetative propagation.

\section{Introdução}

A silvicultura clonal tem como ponto de partida a seleção de genótipos superiores para, posteriormente, proceder-se a sua propagação clonal massal. Geralmente, o processo de seleção desses genótipos é realizado na fase adulta, em que o enraizamento de propágulos vegetativos e a formação de mudas é um grande desafio em razão da idade ontogenética do material.

A maturação do material vegetal em plantas lenhosas, decorrente da transição da fase juvenil para a adulta, tem recebido atenção especial por causa das alterações morfológicas, bioquímicas e fisiológicas que determinam a resposta dos propágulos vegetativos às condições do ambiente de propagação e, posteriormente, ao ambiente de crescimento

\footnotetext{
(1) Aceito para publicação em 20 de dezembro de 2002 .

(2) Embrapa-Centro Nacional de Pesquisas de Florestas, CEP 83411-000 Colombo, PR. E-mail: ivar@cnpf.embrapa.br

(3) Universidade Federal de Viçosa, Dep. de Engenharia Florestal, Avenida P. H. Rolfs, s/n, CEP 36571-000 Viçosa, MG. E-mail: xavier@ufv.br
}

dos povoamentos florestais. No entanto, essas alterações são variáveis entre as diferentes espécies e, mesmo numa mesma espécie, as informações são contraditórias (Hackett, 1987).

São inúmeras as características que sofrem modificações com a troca de fase durante o desenvolvimento das plantas. A redução na capacidade de crescimento em diâmetro e altura com o aumento da maturação pode ser facilmente demonstrada pelo enraizamento de estacas ou pela enxertia de ramos de diferentes idades. Enxertos e estacas juvenis não somente produzem maior crescimento do caule, mas também maior quantidade de folhas e biomassa (Greenwood \& Hutchison, 1993). Segundo esses autores, uma vez que a capacidade de enraizamento decresce com o aumento da maturação, menores crescimentos em altura e diâmetro podem ser resultantes do menor vigor do sistema radicular em propágulos mais maduros.

Uma das mais consistentes expressões da maturação em plantas lenhosas é a transição da alta para a baixa capacidade de enraizamento de estacas caulinares e foliares (Hackett, 1987; Eldridge et al., 1994). Em algumas espécies lenhosas, estacas de mudas jovens (juvenis), provenientes de sementes, 
enraízam facilmente, enquanto outras provenientes de plantas mais velhas enraízam esporadicamente, ou definitivamente não enraízam (Zobel \& Talbert, 1984). Além do aumento dos porcentuais de enraizamento, a maior qualidade e rapidez de formação do sistema radicular também tem sido citada (Gomes, 1987), ou seja, um aumento no vigor radicular (número e comprimento de raízes) em razão de maior juvenilidade dos propágulos (Schneck, 1996).

A estaquia seriada como método de rejuvenescimento em Eucalyptus spp., com possíveis efeitos positivos sobre o enraizamento, foi citada por Eldridge et al. (1994) e alguns trabalhos desenvolvidos por St. Clair et al. (1985) com Picea abies. Entretanto, ainda há carência de informações consistentes em relação a esses aspectos. A miniestaquia seriada pela rapidez no enraizamento e formação de mudas poderá ser um método alternativo promissor no rejuvenescimento de clones de Eucalyptus.

O objetivo deste trabalho foi avaliar a eficiência da técnica de miniestaquia seriada em quatro clones de Eucalyptus grandis, quanto à sobrevivência, ao enraizamento e ao crescimento em altura e diâmetro de colo das mudas.

\section{Material e Métodos}

O experimento foi realizado na Empresa Celulose Nipo-Brasileira S.A. (Cenibra), no Município de Belo Oriente, MG. Foram utilizados quatro clones comerciais de Eucalyptus grandis (CC10, CC12, CC14 e CC15), selecionados para celulose em uma população de procedência de Rio Claro, SP, e propagados vegetativamente a partir da técnica de estaquia convencional. Os clones se encontravam em jardim clonal comercial de campo, de onde foram resgatados pela técnica de estaquia convencional, com manejo e nutrição de acordo com os procedimentos adotados pela Cenibra.

A partir de minicepas formadas de mudas produzidas pelo processo de estaquia convencional (jardim 0 ), foram obtidas as miniestacas, que foram enraizadas em casa de vegetação, com condições ambientais de temperatura em torno de $27^{\circ} \mathrm{C}$ e umidade relativa do ar superior a $80 \%$. As miniestacas, sem a aplicação de reguladores de crescimento, permaneceram em casa de vegetação por 25 dias, em casa de sombra por mais dez dias e, posteriormente, em rustificação a pleno sol; após 20 dias foram podadas para formação das minicepas do subcultivo 1 .
As mudas formadas a partir das miniestacas enraizadas do subcultivo 1, ao atingirem 10 a $12 \mathrm{~cm}$ de altura (em torno dos 60 dias de idade), tiveram seu ápice podado de 6 a $8 \mathrm{~cm}$ da base, formando, assim, as minicepas do subcultivo 2, que, após 20 a 30 dias, forneceram as brotações (miniestacas). As minicepas do subcultivo 2, de forma similar às do subcultivo 1 , forneceram novas miniestacas para formação do jardim miniclonal do subcultivo 3, e assim sucessivamente até o subcultivo 7 . Foram formados sete jardins miniclonais (jardim 0, 1, 2, 3, 4,5 e 6 ), ou seja, sete subcultivos de miniestaquia (subcultivo 1, 2, 3, 4, 5, 6 e 7).

Os jardins miniclonais foram desenvolvidos em sistema de hidroponia em calhetão com areia, e a nutrição mineral balanceada de modo a se obter um bom padrão de vigor das minicepas, conforme Wendling (2002).

Em períodos regulares de 5 a 10 dias, as minicepas receberam podas seletivas para coleta de miniestacas. As podas foram mantidas durante toda a fase experimental, de modo a garantir um manejo adequado de produção de miniestacas nos jardins miniclonais.

Uma vez formados os jardins miniclonais dos sete subcultivos, foram coletadas simultaneamente miniestacas dos jardins de subcultivos 0 (jardim formado de mudas originárias de estacas), 2, 4 e 6 , após sua formação ter sido completada. Destes jardins, foram enraizadas miniestacas e formadas as minicepas para os jardins utilizados na experimentação (jardim miniclonal de subcultivo 1, 3, 5 e 7), os quais forneceram as miniestacas para os testes comparativos.

Esse procedimento, além de facilitar a operacionalização dos testes comparativos entre os subcultivos, buscou também a padronização da idade das minicepas de todos os subcultivos, para posterior coleta de miniestacas.

No enraizamento e formação das mudas, as miniestacas foram enraizadas em tubetes de plástico de $55 \mathrm{~cm}^{3}$, contendo substrato formado pela mistura em partes iguais de vermiculita de granulometria média e casca de arroz carbonizada. Utilizou-se nutrição mineral balanceada, em mistura com o substrato, conforme Wendling (2002).

O delineamento experimental utilizado foi o inteiramente casualizado, em arranjo fatorial $4 \times 4$ (quatro subcultivos e quatro clones), com cinco repetições, sendo cada parcela constituída por 24 miniestacas. Nas avaliações, considerou-se a sobrevivência das miniestacas na saída da casa de vegetação, enraizamento na saída da casa de sombra e sobrevivência aos 50 dias, bem como o crescimento em altura, diâmetro de colo e peso da matéria seca da parte aérea das mudas aos 50 dias. Os dados foram submetidos à análise de variância e as médias comparadas pelo teste de Tukey a $\mathbf{5 \%}$ de probabilidade. 


\section{Resultados e Discussão}

A sobrevivência das miniestacas na saída da casa de vegetação não apresentou diferenças entre os subcultivos estudados, exceto com o clone CC14, indicando o excelente controle ambiental e manejo da casa de vegetação na manutenção do vigor das miniestacas (Figura 1). Xavier et al. (2001), avaliando clones de Eucalyptus spp. no Norte de Minas Gerais, em condições ambientais consideradas mais drásticas de temperatura e manejo, constataram que ocorreram respostas mais pronunciadas dos efeitos do rejuvenescimento in vitro (microestaquia) em termos de sobrevivência, quando comparado com a miniestaquia (sem rejuvenescimento), indicando que a ocorrência dessas diferenças é mais facilmente visível em condições ambientais mais adversas.

O enraizamento na saída da casa de sombra teve comportamento semelhante ao verificado na saída da casa de vegetação (Figura 1). Entre os inúmeros fatores que podem ter contribuído para esses altos índices gerais de sobrevivência na saída da casa de vegetação, e enraizamento na saída da casa de sombra, estão as boas condições de temperatura, umidade e manejo às quais os propágulos foram submetidos, aliadas ao potencial genético favorável dos clones na propagação vegetativa. Além disso, as condições de alto vigor fisiológico das miniestacas, resultantes do sistema de manejo adotado no jardim miniclonal, também constitui fator de grande importância.

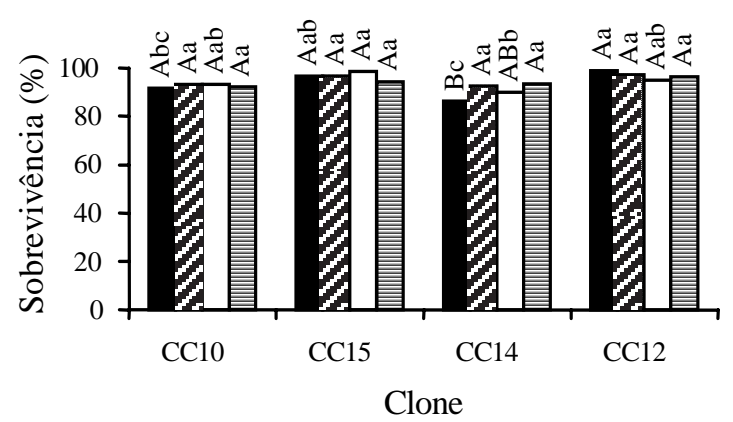

A sobrevivência das mudas aos 50 dias de idade mostrou um efeito mais drástico do ambiente, com ocorrência de diferenças entre os tratamentos e clones, uma vez que as mudas foram submetidas às condições de rustificação (insolação direta, diminuição nas irrigações e adubações). O clone CC12 foi superior aos demais e houve um efeito positivo dos subcultivos na sobrevivência das mudas em relação aos clones $\mathrm{CC} 10, \mathrm{CC} 15$ e CC14, sendo o efeito mais pronunciado no clone CC10 (Figura 2).

Tais constatações sugerem que materiais com menores índices de enraizamento e sobrevivência, como o clone $\mathrm{CC10}$, respondem melhor à miniestaquia seriada, evidenciando a aplicabilidade desta técnica em clones e espécies que apresentam dificuldade de enraizamento (Xavier et al., 2001). Em relação aos clones $\mathrm{CC} 10$ e $\mathrm{CC} 15$, talvez um maior número de subcultivos poderia resultar em efeitos mais pronunciados.

Houve boa taxa de enraizamento de todos os clones, o que permite concluir que a miniestaquia seriada não foi tão eficiente como se esperava.

O enraizamento de propágulos ainda tem sido a característica mais aceita para indicar um resultado de rejuvenescimento (George, 1993; Eldridge et al, 1994; Hartmann et al., 1997). Portanto, a maior sobrevivência resultante dos subcultivos de miniestaquia seriada, principalmente em relação ao clone $\mathrm{CC} 10$, pode estar associada a um efeito de rejuvenescimento.

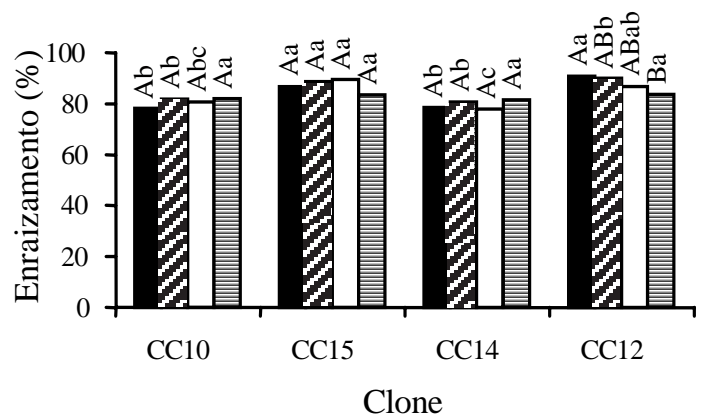

Figura 1. Sobrevivência das miniestacas na saída da casa de vegetação e enraizamento na saída da casa de sombra em razão dos subcultivos ( $\square: 1 ; \mathbb{Z}: 3 ; \square: 5 ; \square: 7$ ) e clones de Eucalyptus grandis. Médias com mesma letra maiúscula dentro de cada clone, entre os subcultivos, e com mesma letra minúscula, entre os clones, dentro de cada subcultivo, não diferem entre si, pelo teste de Tukey a $5 \%$ de probabilidade. 
$\mathrm{Na}$ silvicultura clonal, um dos critérios adotados na seleção de clones de Eucalyptus é o bom índice de enraizamento. Segundo Eldridge et al. (1994), o descarte de clones com baixos índices de enraizamento é importante, uma vez que estes variam de $1 \%$ a $90 \%$ em híbridos de Eucalyptus e, após a seleção, com o descarte dos clones piores, um índice superior a $80 \%$ pode ser obtido, viabilizando a clonagem em escala comercial. Segundo o mesmo autor, o número de clones pode ser drasticamente reduzido e clones com bom potencial produtivo e de qualidade podem ser perdidos. Assim, muitos clones com características de interesse foram descartados

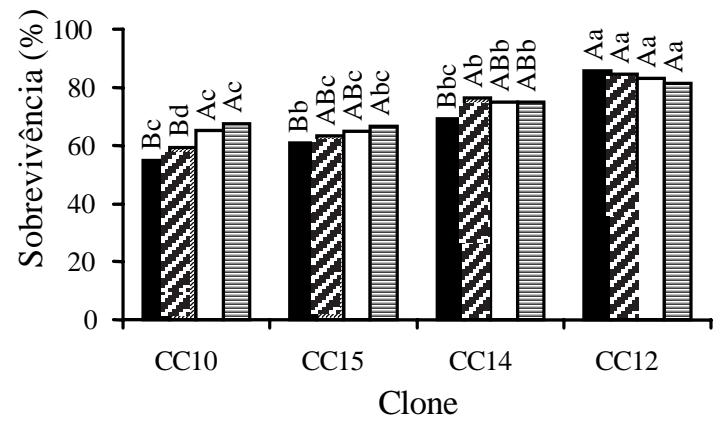

Figura 2. Sobrevivência em casa de sombra das mudas aos 50 dias de idade em razão dos subcultivos ( $\square: 1 ; \square: 3$; $\square: 5 ; \square: 7)$ e clones de Eucalyptus grandis. Médias com mesma letra maiúscula dentro de cada clone, entre os subcultivos, e com mesma letra minúscula, entre os clones, dentro de cada subcultivo, não diferem entre si, pelo teste de Tukey a $5 \%$ de probabilidade.

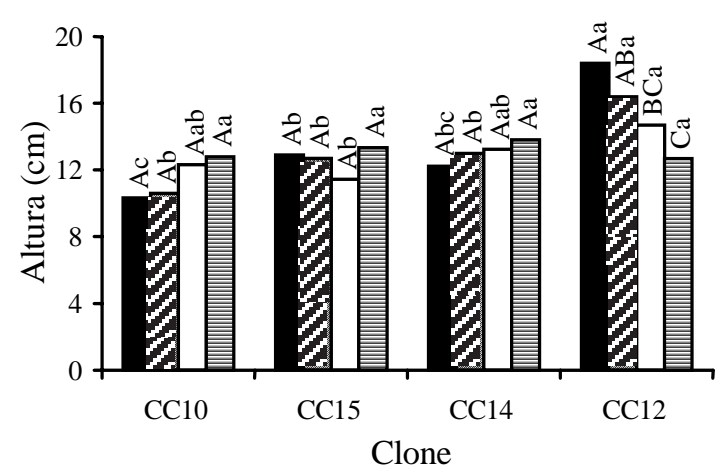

dos programas comerciais em vista dos baixos índices de enraizamento, levando a uma certa homogeneização dos materiais empregados na clonagem comercial quanto ao potencial de enraizamento.

Quanto à altura das mudas aos 50 dias, nos clones $\mathrm{CC} 10, \mathrm{CC} 15$ e CC14 não se verificaram variações significativas com relação ao número de subcultivos (Figura 3). No clone de maior aptidão à propagação vegetativa (CC12), notou-se novamente uma resposta negativa em relação aos subcultivos de miniestaquia seriada. Pelo fato de a altura ser uma característica facilmente modificada em razão do manejo adotado na produção das mudas (Carneiro, 1995), pode-se imaginar efeito dominante desta ação em relação aos resultados promovidos pela miniestaquia seriada. Isto pode ser observado, principalmente quando se trabalha com clones com bom grau de juvenilidade, ou seja, com os altos índices de enraizamento e sobrevivência encontrados, conforme descrito em relação à sobrevivência das mudas aos 50 dias.

Quanto ao diâmetro de colo das mudas e altura aos 50 dias, o clone de maior aptidão à propagação vegetativa (CC12) mostrou efeito negativo em relação ao número de subcultivos de miniestaquia seriada, enquanto o clone de menor aptidão (CC10) apresentou resposta positiva aos subcultivos (Figura 3).

Segundo Boliani (1986), o estado juvenil possibilita maior crescimento da planta, produção de grande superfície foliar e maior produção de fotoassimilados a serem posteriormente utilizados no

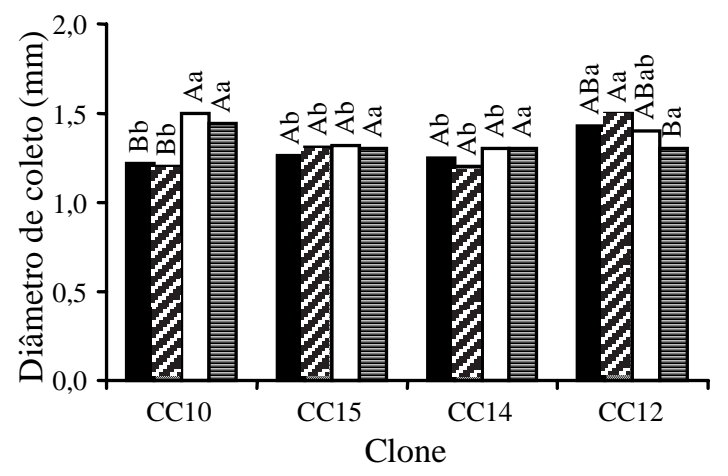

Figura 3. Altura e diâmetro de colo das mudas aos 50 dias de idade em razão dos subcultivos ( $\square: 1 ; \square: 3 ; \square: 5 ; \square: 7$ ) e clones de Eucalyptus grandis. Médias com mesma letra maiúscula dentro de cada clone, entre os subcultivos, e com mesma letra minúscula, entre os clones, dentro de cada subcultivo, não diferem entre si, pelo teste de Tukey a 5\% de probabilidade. 
crescimento e desenvolvimento geral das plantas. Tais conclusões permitem explicar, pelo menos em parte, a resposta positiva da miniestaquia seriada sobre o diâmetro de colo das mudas obtidas, principalmente com o clone CC10.

De forma geral, quando se analisam as características de sobrevivência, altura e diâmetro de colo das mudas aos 50 dias de idade, nota-se efeito positivo da miniestaquia seriada no rejuvenescimento somente em relação aos clones de Eucalyptus grandis com menor aptidão ao enraizamento de propágulos. Nos clones de boa aptidão à propagação vegetativa não se observa efeito positivo da miniestaquia seriada. Resultados semelhantes foram obtidos por Titon (2001) e Xavier et al. (2001), no rejuvenescimento in vitro.

Quanto ao peso da matéria seca da parte aérea das mudas aos 50 dias, não foi observada diferença entre os subcultivos, dentro de cada clone, com exceção do clone $\mathrm{CC} 12$, que apresentou resultados superiores nos subcultivos 1 e 3 (Figura 4). Segundo Boliani (1986) e Greenwood \& Hutchison (1993), o estado juvenil possibilita o maior crescimento da planta e a produção de grande superfície foliar. Em razão da ausência de resposta dos clones CC10, CC15 e CC14 aos subcultivos, pode-se sugerir que eles apresentavam bom grau de juvenilidade para essa característica.

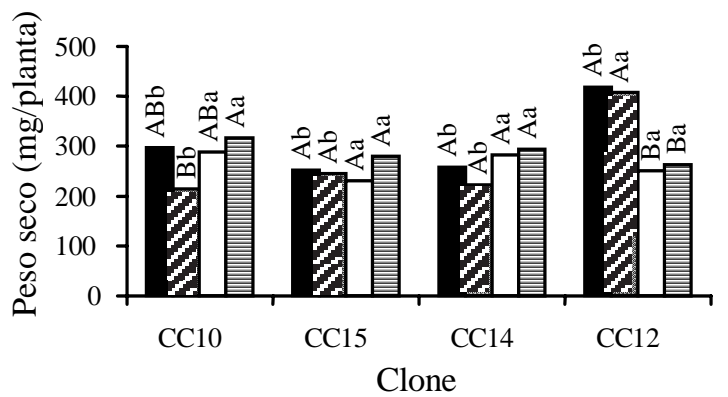

Figura 4. Peso da matéria seca da parte aérea das mudas aos 50 dias de idade em razão dos subcultivos ( $\square$ : 1; 叉: 3; $\square: 5 ; \square: 7)$ e clones de Eucalyptus grandis. Médias com mesma letra maiúscula dentro de cada clone, entre os subcultivos, e com letra minúscula, entre os clones, dentro de cada subcultivo, não diferem entre si, pelo teste de Tukey a $5 \%$ de probabilidade.
Em clones de Eucalyptus grandis, Titon (2001) e Xavier et al. (2001) concluíram que maiores respostas ao rejuvenescimento, pela técnica de microestaquia (material rejuvenescido por sucessivos subcultivos in vitro) ocorrem em clones menos propensos à propagação vegetativa, sugerindo efeitos mais significativos dos métodos de rejuvenescimento em materiais menos juvenis.

Os resultados obtidos do presente trabalho indicam a potencialidade da técnica de miniestaquia seriada como método de rejuvenescimento em relação aos clones de Eucalyptus grandis com baixo potencial de enraizamento. Em clones com maior potencial de enraizamento, como o CC12, não se observa efeito, verificando até mesmo uma redução dos índices de enraizamento, sobrevivência e vigor com o aumento dos subcultivos de miniestaquia seriada, o que pode estar relacionado a uma perda de vigor fisiológico destes materiais com o aumento dos subcultivos, possível conseqüência do estresse induzido pelas contínuas manipulações dos propágulos.

\section{Conclusões}

1. A técnica de miniestaquia seriada é indicada no rejuvenescimento de clones de Eucalyptus grandis com baixo potencial de enraizamento em relação ao enraizamento, à sobrevivência e ao vigor radicular e aéreo.

2. O grau de rejuvenescimento promovido pela miniestaquia depende de características dos clones.

3. A utilização de clones mais contrastantes quanto ao porcentual de enraizamento permite maior compreensão da eficiência da miniestaquia seriada como método de rejuvenescimento.

\section{Agradecimentos}

À Celulose Nipo-brasileira S.A., pela cessão do material experimental, pelo apoio orçamentário e estrutural; à Fundação de Amparo à Pesquisa do Estado de Minas Gerais e à Federação das Indústrias de Minas Gerais, pela bolsa de estudos; à Empresa Brasileira de Pesquisa Agropecuária, pelo apoio pessoal. 


\section{Referências}

BOLIANI, A. C. Efeitos do estiolamento basal, da juvenilidade e do uso de um regulador vegetal no enraizamento de estacas de raízes e de ramos herbáceos de algumas espécies frutíferas. 1986. 129 f. Dissertação (Mestrado em Agronomia) - Escola Superior de Agricultura Luiz de Queiroz, Piracicaba, 1986.

CARNEIRO, J. G. A. Produção e controle de qualidade de mudas florestais. Curitiba: UFPR/Fupef, 1995. $451 \mathrm{p}$.

ELDRIDGE, K.; DAVIDSON, J.; HARDWIID, C.; WYK, G. V. Eucalypt domestication and breeding. Oxford: Clarendon, 1994. p. 228-246.

GEORGE, E. F. Plant propagation by tissue culture: the technology. Edington: Exegetics, 1993. v. 1.

GOMES, A. L. Propagação clonal: princípios e particularidades. Vila Real: Universidade de Trás-os-Montes e Alto Douro, 1987. 69 p. (Série Didáctica, Ciências Aplicadas, 1).

GREENWOOD, M. S.; HUTCHISON, K. W. Maturation as an developmental process. In: AHUJA, M. R.; LIBBY, W. J. (Ed.). Clonal forestry: genetics and biotechnology. Budapest: Springer, 1993. p. 14-33.

HACKETT, W. P. Donor plant maturation and adventitious root formation. In: DAVIES, T. D.; HAISSIG, B. E.; SANKHLA, N. (Ed.). Adventitious root formation in cuttings. Portland: Dioscorides, 1987. p. 11-28. (Advances in Plant Sciences Series, 2).
HARTMANN, H. T.; KESTER, D. E.; DAVIES JUNIOR, F. T.; GENEVE, R. L. Plant propagation: principles and practices. 6th ed. Upper Saddle River: Prentice-Hall, 1997. $770 \mathrm{p}$.

SCHNECK, V. Untersuchungen zur Klonabhängigkeit der Bewurzelungsfähigkeit und der Qualität er Wurzelbildung bei der Stecklingsvermehrung von 40 - bis 350 jährigen Auslesebäumen der Eibe (Taxus baccata). Silvae Genetica, Frankfurt, v. 45, n. 5/6, p. 246-249, 1996.

ST. CLAIR, J. B.; KLEINSCHMIT, J.; SVOLBA, J. Juvenility and serial vegetative propagation in Norway spruce clones (Picea abies). Silvae Genetica, Frankfurt, v. 34, n. 1, p. 422-448, 1985.

TITON, M. Propagação clonal de Eucalyptus grandis por miniestaquia e microestaquia. 2001. $65 \mathrm{f}$. Dissertação (Mestrado em Ciência Florestal) - Universidade Federal de Viçosa, Viçosa, MG, 2001.

WENDLING, I. Rejuvenescimento de clones de Eucalyptus grandis pela técnica de miniestaquia e micropropagação seriada. 2002. 98 f. Tese (Doutorado em Ciência Florestal) - Universidade Federal de Viçosa, Viçosa, MG, 2002.

XAVIER, A.; ANDRADE, H. B.; OLIVEIRA, M. L.; WENDLING, I. Desempenho do enraizamento de microestacas e miniestacas de clones de híbrido de Eucalyptus grandis. Revista Árvore, Viçosa, MG, v. 25, n. 4, p. 403-411, 2001.

ZOBEL, B.; TALBERT, J. Applied forest tree improvement. New York: North Carolina State University, 1984. $505 \mathrm{p}$. 